\title{
ESPAÇOS DELIBERATIVOS E A QUESTÃO DA REPRESENTAÇÃO
}

\author{
Céli Regina Jardim Pinto
}

Este artigo tem como propósito discutir a relação entre os princípios de participação e representação nas atuais teoria e prática democráticas, que entendem o regime como potencialmente capaz de gerar justiça e inclusão social. É consenso entre um número significativo de autores que a democracia representativa tal como se consolidou no século XX não tem sido capaz de dar conta dos sérios problemas sociais e culturais que o mundo contemporâneo apresenta. Sejam seus limites entendidos como decorrência de uma crise da representação, sejam vistos como uma condição da própria natureza da democracia representativa, a solução encontrada pelos críticos aponta para formas alternativas de participação, tanto no sentido de substituir a representação, como no de criar instrumentos que favoreçam a accountability.

Artigo recebido em novembro/2002 Aprovado em setembro/2003
Parte-se aqui de uma pergunta e uma assertiva. Até que ponto a substituição da representação pela participação como forma de solucionar os problemas da democracia representativa não incorre nos mesmos limites delineados por esta, sem que, no entanto, se possa manter suas salvaguardas? As potencialidades de radicalização dos princípios da democracia decorrem da combinação entre representação e participação, em que a participação deve estar ao mesmo tempo suficientemente independente do campo da política institucional, para estabelecer com ela uma relação calcada na autonomia e não caudatária de interesses construídos no seu interior, e inserida o bastante nesse campo para que não ocorra uma espécie de divisão de trabalho entre sociedade civil e a esfera propriamente política. Para desenvolver essas questões, proponho, na primeira parte deste artigo, o levantamento, ainda que breve, de alguns casos já estudados de experiências de participa- 
ção, apontando, a meu ver, questões fundamentais para o avanço da discussão. Na segunda parte, discutirei três capítulos do mais recente livro da cientista política norte-americana Iris Young sobre democracia (Inclusion and democracy), em que a questão do encontro dos princípios de participação e de representação é um tema central. Finalmente, à guisa de conclusão, retomarei a assertiva inicial a partir de uma releitura das experiências relatadas na primeira parte à luz das teses desenvolvidas por Young.

\section{Experiências deliberativas}

O conjunto de experiências aqui relatadas faz parte dos resultados de um extenso projeto de pesquisa intitulado "Reinventar a Emancipação Social: Para Novos Manifestos", dirigido por Boaverntura de Souza Santos, em que foram feitos estudos de casos em países da América Latina, da África, da Ásia e da Europa. As experiências que serão aqui relatadas foram escolhidas por serem exemplos de duas situações muito significativas, que me interessam particularmente examinar no contexto da discussão proposta: virtual ausência de Estado e organização da sociedade civil estreitamente relacionada com governos de partidos de esquerda. ${ }^{1}$

As duas primeiras experiências de que tratarei ocorreram na Índia e na África do Sul, e no que pese as profundas diferenças culturais que as separam dividem algumas características importantes. A primeira diz respeito aos micromovimentos surgidos na Índia, sobretudo na década de 1970, e que, segundo estimativas, atingiram o impressionante número de três mil (cf. Sheith, 2002). Nesse cenário, o que primeiro chama a atenção é a crise das instituições políticas: após um período de políticas de inclusão dos grupos mais desfavorecidos no processo político eleitoral, durante as décadas de 1960 e 1970, o processo sofreu um refluxo, principalmente com a determinação de estado de sítio no período de 1975 a 1977, durante o governo de Indira Gandhi.

[...] estes grupos-movimentos que hoje identificamos emergiram e consolidaram-se nos espaços de intervenção que foram sendo deixados pelo declínio das instituições tradicionais da democracia representativa: legislaturas, eleições, partidos políticos e sindicatos (Idem, p. 89).

Durante o estado de sítio, esses grupos prestavam, inclusive, serviços jurídicos à população para garantir direitos ameaçados pela situação política. Os movimentos sofreram novamente um refluxo na década de 1980 e início dos anos de 1990, mas ressurgiram em meados desta década. Da descrição das atividades de vários desses grupos interessa dois aspectos, estreitamente relacionados, a saber, o caráter político não partidário e a presença de líderes de grande peso. A concepção de movimento político não partidário está diretamente ligada à idéia de democracia participativa e tem, ademais, inspiração na pregação de Ghandi e, posteriormente, na liderança de Jayaprakash Narayan, seu seguidor que

Era crítico da idéia da representação por partidos políticos e defendia uma forma mais participativa e abrangente de democracia que constituísse uma base democrática ampliada a partir da qual o poder brotaria e ascenderia para células que utilizariam o poder que lhes fora atribuído pelas células inferiores; tudo isto em condições de responsabilização e transparência (Sheith, 2002, p. 114).

Muitos dos movimentos que surgiram no final do século XX, derivados da liderança de Narayan, tiveram êxito certamente por causa da presença de fortes lideranças, e resultaram em experiências importantes de participação, das quais duas me interessam particularmente, pois são momentos de relação direta entre os movimentos e a política institucional. Uma petição apresentada ao Supremo Tribunal da Índia solicitou o fechamento de uma minas de calcita, que ameaçava a saúde da população e o equilíbrio ecológico. A vitória da causa propiciou uma grande mobilização nacional pela garantia da execução das determinações do tribunal e pelo alastramento da luta contra políticas que afetassem direitos ligados à terra e à biodiversidade (Campanha pelo Controle do Povo sobre Recursos Naturais). De outro caráter, a segunda experiência diz respeito à mobilização em torno da luta pela garantia de pagamen- 
to legal do salário aos operários da construção civil em obras públicas. O movimento começou em uma cidade com o lançamento da campanha ao direito à informação; atingiu tamanha mobilização que as autoridades foram obrigadas a mudar a lei, criando recibos de pagamento público. A Campanha pelos Direitos do Povo à Informação alcançou uma dimensão estadual, gerando leis que, hoje, estão sendo discutidas pelo Parlamento em âmbito nacional (Sheith, 2002, p. 123).

Embora muitas das experiências terem obtido resultados positivos e envolvido um grande número de pessoas, atingindo dimensões nacionais, o que em se tratando de um país como a Índia tem um significado particular devido à sua imensa população, a questão que eles levantam é a de até onde esses movimentos não tem uma evolução na direção de grande campanhas populares de massa com fortes lideranças, como ocorreu em relação aos movimentos mencionados acima. Não há dúvida quanto ao sentido de mobilização e pressão popular que esses movimentos contêm e dos resultados que atingiram na esfera política, tanto no judiciário como no legislativo. Não resta dúvida também que eles constituem uma forma vigorosa de participação popular; no entanto, não parecem criar canais regulares de participação no sentido de mudar as regras do jogo democrático. A intervenção ocorre como correção a um Estado que não funciona, o que suscita uma outra questão, relacionada ao sentido não partidário desses movimentos. As reivindicações, os grupos que defendem e as políticas que buscam implementar não deixam qualquer dúvida sobre o fato de se tratar de movimentos estreitamente associados ao que se identifica como propostas políticas de esquerda. Não obstante Sheith enfatizar a tradição indiana de não partidarismo, enraizada no próprio movimento de Gandhi pela Independência, este parece ser um fenômeno mais amplo nos atuais processos participativos, presentes em muitas manifestações, inclusive em países como o Brasil, e que revela uma das questões basilares na relação entre processos participativos e partidos políticos, pois o partido permanece com o monopólio do acesso aos cargos eletivos, havendo uma espécie de divisão do trabalho, o que será desenvolvido no decorrer desta análise.

Apesar das profundas diferenças culturais e de contexto histórico, uma outra experiência permite avançar na discussão levantada pelos exemplos indianos. Trata-se de experiências de participação na África do Sul durante o regime do apartheid (Buhlungu, 2002), as quais tiveram grande crescimento durante a década de 1980 e deram seguimento a uma idéia de auto-governo, presente na tradição da luta política do país desde a década de 1950. Foram criados comitês de rua, de área, tribunais populares e assembléias representativas de estudantes. Os comitês eram a base para uma bem montada organização a partir da qual, por eleições sucessivas, se chegava a um órgão municipal chamado de organização cívica. Os tribunais populares apareciam como uma alternativa às injustiças do regime do apartheid. O que interessa particularmente em relação à experiência da África do Sul é, de um lado, o sucesso da experiência no contexto do regime do aparthied e, do outro, sua incapacidade de gerar formas novas de participação quando o regime foi derrotado e um novo pacto se constituiu. O sucesso da experiência estava associado à exclusão total da população negra do país de qualquer espaço político. É da exclusão e, portanto, da ausência do Estado como provedor, uma vez que ele só esteve presente na vida dessas populações como agente de repressão e como executor de políticas discriminatórias, que a experiência frutificou:

Até certo ponto o período entre meados dos anos de 1980 e princípios dos anos de 1990 foi um desses períodos na África do Sul em que as instituições e as políticas alternativas substituíram, ainda que temporariamente, as instituições hegemônicas do regime do apartheid (Buhlungu, 2002, p. 157).

O processo na África do Sul é um caso exemplar de experiência participativa que entra em declínio com a abertura política, que, naquele país, foi liderada pelo African National Congress. Buhlungu atribui o declínio a fatores como a natureza negociada da transição, o personalismo e a falta de experiência das lideranças que voltavam do exílio ou saiam de longos períodos de prisão, e 
até mesmo ao colapso do bloco soviético, que desmobilizou propostas de transformação social (Idem, p. 163). Não é meu propósito aqui entrar no mérito sobre as causas do fracasso da experiência levantadas pelo autor, mesmo porque não disponho de dados para contrapor seu argumento. Entretanto, gostaria de chamar atenção para a coincidência entre o estabelecimento de uma democracia representativa e o declínio da experiência participativa. Se essa experiência obteve êxito em condições tão adversas como as do regime do apartheid sul-africano, como explicar seu fracasso atribuindo à maneira pela qual esse regime foi derrotado? Até que ponto a participação, neste caso, ocorreu como um fenômeno outsider à política, ou melhor, que embora não fosse político, estivesse no lugar da política, à maneira dos movimentos não partidários da Índia?

As experiências da Índia e da África do Sul permitem trazer para a discussão duas questões centrais no que concerne a relação entre participação e representação. A primeira diz respeito à relação entre experiências participativas com a democracia representativa. Em qualquer um dos casos, esta relação ou não existiu, ou foi de enfrentamento. Na África do Sul, não existiu em duas circunstâncias paradoxais, ou porque não havia democracia ou porque a própria experiência perdeu fôlego com a instauração da democracia. Na Índia, a relação ocorreu ou pelo fracasso das instituições, ou pelo enfrentamento, na forma de movimento popular de massa de caráter reivindicatório.

A segunda questão relevante é a independência da participação popular em relação aos partidos políticos. Esse fato é especialmente significativo, uma vez que se tratam de dois países com sociedades civis bastante fragilizadas e com escassas experiências de construção de esferas públicas, e, portanto, viveiros quase naturais de experiências que se caracterizam por esse tipo de independência em relação a partidos políticos. Essa situação, oriunda seja da tradição, seja do descrédito, ou mesmo da total falta de espaço aos partidos existentes, apresenta um novo cenário, o qual pode ser analisado sob duas perspectivas: "despartidarização" da política ou politização da sociedade. Em qualquer um dos casos a conseqüência parece ser a deslegitimação do espaço da política institucional.
Gostaria, neste momento da análise, de focar duas outras experiências de participação com características completamente diversas das duas anteriores. Trata-se das experiências de descentralização do planejamento no Estado de Kerala, na Índia (Heller e Isaac, 2002), e do orçamento participativo em Porto Alegre, no Brasil (Santos, 2002a; Avritzer, 2002). Em 1996, assume o poder no Estado de Kerala uma coligação de esquerda, a Frente Democrática de Esquerda liderada pelo Partido Comunista, e, neste mesmo ano, implanta-se a Campanha dos Cidadãos pela Descentralização do Planejamento. Ela se constituiu de uma profunda e bem organizada experiência de democracia participativa em um Estado onde a população é 31 milhões de habitantes. Organizaram-se 1.214 órgãos locais, juntamente com "programas massificados de formação, de mobilização efetiva das competências da sociedade civil e de esforços coordenados de transferência de poder para grupos tradicionalmente marginalizados - mulheres, adivasis (tribais) e dalits (intocáveis)" (Heller e Isaac, 2002, p. 603). Para esses grupos foram, inclusive, asseguradas cotas de participação e de recursos no planejamento. Não cabe aqui detalhar as diversas fases do planejamento descentralizado, mas cabe enfatizar de que se tratou de uma sofisticada engenharia, composta de vários níveis de assembléias, centros de formulação de projetos, desde suas organizações mais locais até encontros estaduais.

A experiência de Kerala é muito próxima da de Porto Alegre. O Partido dos Trabalhadores vem governando o município desde 1989, onde se concretizou uma forte experiência de democracia participativa por meio do Orçamento Participativo. A exemplo da experiência do Estado indiano, o OP, como ficou conhecido, funciona a partir de um complexo conjunto de assembléias:

[...] o OP está articulado em torno das assembléias plenárias regionais e temáticas, dos fóruns delegados e do Conselho do OP. Há dois ciclos de assembléias plenárias em cada uma das dezesseis regiões e em cada uma das seis áreas temáticas. Entre as duas rodadas são realizadas reuniões preparatórias nas microregiões e nas áreas temáticas (Heller e Isaac, 2002, p. 471). 
Essas duas experiências de democracia participativa têm uma natureza completamente distinta daquelas analisadas anteriormente. Enquanto o grupomovimento na Índia e as organizações locais na África do Sul foram frutos de uma relação de tensão com as autoridades constituídas e se apresentavam claramente como alternativas ao Estado, as experiências de Kerala e Porto Alegre floresceram porque tanto o Estado indiano como a cidade brasileira são governados por partidos políticos de esquerda que têm como projeto esse tipo de participação. As experiências concretizaram-se a partir de organizações da sociedade civil e, em tese, mantêm uma relação de independência com a política institucional. Entretanto, as condições de funcionamento dos sofisticados processos de tomada de decisão nesses espaços participativos têm sido dadas pelos governos: em Kerala, a campanha pela descentralização foi concebida e organizada pelo Departamento de Planejamento Estatal; em Porto Alegre, os assuntos relacionados ao OP são dirigidos por um órgão ligado diretamente ao Gabinete do Prefeito.

A participação direta do cidadão no planejamento e no orçamento é uma política desejada pelos partidos de esquerda no governo pelo menos por três razões. Em primeiro lugar pela própria postura política ideológica desses partidos, que defendem o alargamento da democracia e da inclusão social. A segunda diz respeito à sua incapacidade de formar legislativos majoritários em seus governos; e, agindo dessa forma, as decisões dos corpos participativos rompem com práticas clientelistas e retiram poder de decisão dos adversário políticos Por fim, não se pode deixar de levar em consideração o fato de que os governos nos países em exame, sejam municipais, estaduais ou federais, atuam em cenários de grande escassez de recursos e de carência de serviços básicos para as populações pobres. A inclusão dessas populações no sentido de tomarem decisão sobre as formas de aplicação dos recursos escassos contribui para a legitimação da própria aplicação.

Contudo, o sucesso dessas experiências não pode ser creditado somente à presença de partidos de esquerda nos respectivos governos, mas é fundamental para o entendimento do fenômeno uma outra característica comum aos dois cenários: em ambos os casos observa-se uma longa tradição de organização da sociedade civil. Ou seja, quando o Partido Comunista, em Kerala, e o Partido dos Trabalhadores, em Porto Alegre, assumiram o governo encontraram uma sólida tradição participativa. Segundo Heller e Isaac

[...] a longa história de mobilização social iniciada com movimentos de reforma do sistema de castas e algumas revoltas pontuais nos anos de 1920 e 1940 cristalizaram-se em um movimento das classes populares sob a proteção do partido comunista, que ascendeu ao poder em 1957. Sucessivos mandatos comunistas, juntamente com um processo quase contínuo de mobilização militante massificada, exerceram uma pressão inflexível no poder central para a ampliação de programas sociais, o controle do mercado de trabalho e a implantação de reformas agrárias (Heller e Isaac, 2002, p. 610).

Também Porto Alegre tem um tradição política de esquerda e uma experiência de associativismo e organização nos bairros que data da década de 1950. Segundo David:

Embora já houvesse alguma movimentação prévia, é difícil falar em Movimentos antes da segunda metade dos anos de 1970. Já existiam muitas Associações de Moradores no Município desde a década de 1950, organizadas em torno da Federação Rio-grandense de Associações Comunitárias e Amigos de Bairro (Fracab), fundada no mesmo decênio. Essa entidade encontrava-se, nos anos de chumbo, sob a dependência financeira e política do Estado, mas em 1977, havia se reorganizado tornando-se um lugar de referências, encontros, trocas de experiências e construção de redes de solidariedade entre os Movimentos. Uma das primeiras lutas que a Instituição encampou se deu em 1979, quando mobilizou uma série de setores populares para garantir o direito de autonomia das entidades de bairros, impedindo que fosse aprovado, na Câmara de Vereadores, um dispositivo de tutela do Estado (David, 2000, p. 1).

Tal característica indica que essas experiências participativas, no que pese serem marcadas por governos de esquerda, não derivam, apenas deles, seu sucesso. Observa-se nessas regiões uma tradição participativa, concretizada em movimentos co- 
munitários, operários etc. Isso é particularmente importante, pois permite entender por que tentativas de repetição da experiência como a do OP em outros cenários nem sempre obtiveram sucesso.

Finalmente, vale acrescentar ainda um outro dado que não pode ser desprezado na análise do êxito das políticas participativas nessas regiões: em ambas, observam-se níveis de desenvolvimento muito superiores se comparados às demais regiões de seus respectivos países. O Estado de Kerala, em 1996, quando o Partido Comunista voltou ao poder,

[...] tinha mais de $90 \%$ de sua população alfabetizada e a esperança de vida atingia 72 anos. Nos últimos trinta anos, a percentagem de famílias abaixo da linha de pobreza diminuiu a um ritmo superior ao de qualquer outro estado indiano, passando de 54,2\%, em 1973-1974, para 24,4\%, em 1987-1988 (Heller e Isaac, 2002, p. 610).

O Estado do Rio Grande do Sul, cuja capital é Porto Alegre, apresenta também índices diferenciados em relação ao restante do país:

[...] apresenta alguns dos melhores indicadores sociais do país. [...] a esperança de vida no Estado é de 68 anos para os homens e 76 para as mulheres, a mais elevada de todas quando comparado com outros Estados brasileiros, tendo a taxa de mortalidade infantil baixado, nas duas últimas décadas, de 52,6 para 18,4 em cada mil crianças com menos de um ano de idade. Na cidade de Porto Alegre essa taxa foi reduzida de 37,2 óbitos em 1980 para 12,2, o que constitui o melhor desempenho entre todas as capitais brasileiras (Santos, 2003, p. 463).

Assim, estamos diante de conjunturas particulares, em que a gestão de governos de partidos de esquerda se faz em cidades com tradição de sociedade civil organizada e com índices socioeconômicos que superam em muito as condições de seus países. Deparamo-nos aqui com uma espécie de círculo vicioso ou virtuoso de complicada resolução: poder-se-ia argumentar que a participação é conseqüência de uma sociedade organizada, em que os indivíduos possuem melhores condições sociais, econômicas e educacio- nais, o que, por sua vez, os leva a votar em partidos mais identificados com causas sociais e com questões concernentes à participação democrática. Se a democracia participativa necessita dessas condições para se desenvolver, como pensar na alteração dessas condições em países ou regiões de extrema pobreza e onde domina partidos oligárquicos, responsáveis por políticas excludentes. Para analisar de forma mais positiva essa problemática é necessário escapar da armadilha, tantas vezes presentes na reflexão sobre a sociedade, de uma espécie de etapismo, onde ao se estabelecer precondições para que uma dada situação ocorra, se está estabelecendo a priori as condições para que ela não ocorra.

Retomando a questão da relação entre participação e representação à luz das quatro experiências apresentadas, parece haver uma característica comum apesar da imensa diversidade entre elas: em todas o princípio de democracia participativa aparece como um antídoto à democracia representativa. Em nenhum dos casos a participação reforça a representação ou busca melhorar sua qualidade; ao contrário, procura isolá-la ou reduzir seu poder, caracterizando-se como um pólo de tomada de decisão e de iniciativa política independente, que pressiona "de fora". Com referência aos movimentos na Índia ou às organizações da África do Sul, o Estado democrático de direito, ou por suas limitações, no primeiro caso, ou simplesmente por não existir no segundo, sempre ocupou, de acordo com essa perspectiva, uma posição de adversário. Na África do Sul é interessante observar que a constituição do Estado democrático foi responsabilizada pelo declínio do movimento. Além disso, nessas duas circunstâncias os partidos foram considerados desagregadores, isto é, na Índia, como vimos, os movimentos estavam calcados em uma tradição não partidária e assistiu-se a uma perda de capacidade em arregimentar militantes; no caso africano, a constituição do partido após a liberação do regime foi apontada como responsável pela desmobilização do movimento participativo. A situação de Kerala e Porto Alegre divide com os outros casos a mesma tensão em relação aos princípios de representação, mas ao contrário daqueles, é permeada por 
uma vontade partidária clara. De todo o modo, em ambos os casos as relações estabelecidas entre o governo, e em conseqüência entre os partidos de esquerda, a sociedade civil organizada e o poder executivo limitam o poder legislativo, espaço por excelência da representação.

\section{Inclusão e democracia}

Não é meu propósito reinterpretar os acontecimentos discutidos anteriormente à luz da análise dos conceitos básicos desenvolvidos por Iris Young no livro Inclusion and democracy a respeito da relação entre participação e representação, mas fazer um comentário denso a esse trabalho no sentido de avançar a discussão proposta.

Young parte da premissa básica de que a democracia é um meio de promover justiça e inclusão, e para isso se faz necessário refletir sobre os processos de participação e representação em condições de desigualdade estrutural. Ela argumenta em favor de uma proposta de democracia deliberativa, assim definida:

No entendimento deliberativo da prática democrática, democracia não é somente um meio pelo qual cidadãos podem promover seus interesses e colocar o poder dos governantes em xeque. Ela também significa um meio de resolver os problemas coletivamente, e depende para sua legitimação e bom andamento da crítica de opiniões diversas de todos os setores da sociedade (Young, 2000, p. 6). ${ }^{2}$

A partir desta perspectiva, a atuação do cidadão na construção do processo democrático toma rumos muito diversos dos estabelecidos pela democracia representativa.

As propostas de democracia que advogam um aumento da participação não estão se referindo ao número de vezes que os cidadãos participam, mas às formas como participam e, mais especificamente, em nome de que e de quem participam. Em uma democracia representativa, todos os cidadãos maiores de idade que estão no gozo de seus direitos políticos participam do processo elegendo representantes para os poderes le- gislativos e chefes do executivo, em caso de regimes presidencialistas. A questão assume, portanto, contornos de outra natureza e diz respeito à exclusão de posicionamentos na formação do cidadão eleitor, isto é, seu direito a manifestar-se não considera condições particulares como classe, raça, etnia, gênero etc. Nas sociedades contemporâneas essas diferenças têm se organizado e, muitas vezes, alcançam uma expressão significativa nos movimentos sociais, contudo não apresentam a mesma força no espaço estritamente político. Parece haver um grande descompasso entre a capacidade de novos sujeitos ou grupos se constituírem publicamente na sociedade civil e conseguirem uma presença pública marcante na esfera política, sobretudo nas instâncias de representação. A relação desses grupos com a democracia é central no primeiro capítulo do livro de Young, intitulado "Social difference as political resource". A autora critica os que vêem os grupos sociais organizados como uma ameaça à democracia, no sentido de que poriam em risco a construção do bem comum; argumenta que as diferenças sociais são, ao contrário, um recurso à democracia, apontando que o problema aparece quando se reduz a questão da diferença à de identidade. Isso é relevante para a discussão das formas de participação, pois ao estabelecer uma distinção entre diferença social e identidade, Young revela a falácia subjacente ao fato de se definir como identidade o grupo e a diferença que lhe dá forma. Em contrapartida, propõe um conceito relacional:

[...] o que faz um grupo um grupo é menos algum conjunto de atributos que seus membros compartilham do que as relações nas quais eles se posicionam ante os outros. Dessa forma, a diferença social pode ser forte ou fraca, ela pode ser mais ou menos saliente, dependendo do ponto de vista da comparação (2000, p. 90).

Daí ser possível pensar que a constituição de grupos em um determinado cenário não significa um estabelecimento definitivo, o qual definirá e marcará o lugar dessas pessoas para sempre no espaço público, tornando impossível a construção de consensos ou o surgimento de novos grupos que ocupem os mesmos espaços. 
A perspectiva relacional pautada na definição da diferença permite imaginar que em uma sociedade pessoas que vivam de forma completamente separada e dispersa e com muito pouca identidade entre si possam se sentir e passem a agir como um grupo coeso por conta de uma determinada circunstância. É bastante possível, por exemplo, pensar essa situação em relação aos atentados de 11 de setembro de 2001 nos Estados Unidos. Criou-se ali a possibilidade de constituição de uma identidade "islâmica" que, antes desses acontecimentos, estava segmentada por etnias, nacionalidades, seitas, classes sociais e até mesmo pelo desejo de inserção na sociedade norte-americana. Ao serem expostas como inimigos e, portanto, verem sua vida cotidiana e seus hábitos ser encarados com suspeita, certamente as diferenças entre as comunidades islâmicas arrefeceram, e a identidade do grupo começou forçosamente a se estabelecer. Muitos outras situações poderiam ser apresentadas nessa mesma direção, como, por exemplo, a constituição do sentimento de pertencimento a um grupo por parte de estrangeiros das mais variadas nacionalidades, culturas, religiões, vivendo em países de cultura xenofóbica.

Young introduz outra noção fundamental para se entender as políticas da diferença, a saber, o conceito de estrutura. Ela afirma que muito do que se identifica como cultural é, na realidade, estrutural:

Considerando que as circunstâncias de vida de um indivíduo contenha muitos meandros de dificuldade ou de diferença, é provável que, tomados um a um podem aparecer como sendo o resultado de decisões, preferências e acidentes. Quando são, entretanto, considerados em conjunto e comparados com a história de vida de outras pessoas, eles revelam uma rede de relações restritas e reforçadas (2000, p. 93).

A partir dessa definição, Young exemplifica a diferença de gênero como sendo estrutural, uma vez que está presente em todas as ações do indivíduo, condicionando sua posição social e suas oportunidades. Mesmo concordando com essa idéia, deve-se ter em mente que a estrutura, no entanto, não determina comportamentos e tomada de posição na esfera pública: as condições estruturais certamente determinam, por exemplo, as oportunidades das mulheres na sociedade, mas não se pode daí inferir uma tomada de posição como sujeito político, constituído a partir dos condicionantes estruturais. A questão deve ser vista com cuidado: ainda tomando as mulheres como exemplo, para que um grupo social se constitua como diferente e se apresente publicamente como um grupo feminista, observa-se aí a atuação de um processo claro de identidade, que não está inscrito em todos os indivíduos do sexo feminino, ainda que as condições estruturais estejam agindo sobre todos. O problema com essa noção não está na constituição da identidade em si, mas na idéia de que a identidade seja condição para que se possa estabelecer uma política de diferença - a questão passa por uma definição essencialista de identidade, que tem raízes em uma concepção fundamentalmente culturalista. Isso é crucial, levando em consideração os temas centrais de que se ocupa este artigo, pois políticas da diferença e de identidades estão relacionadas diretamente com processos participativos ou com processos de "política de presença", ${ }^{3}$ em que a representação é mediada por instrumentos do tipo "cotas". O reconhecimento dos grupos sociais como espaços legítimos do discurso político pode levar a duas situações contraditórias e igualmente perversas. De um lado, o grupo tornar-se um gueto e, por conseguinte, seus membro apenas terem voz a partir das demandas associadas à sua identidade; de outro, pode acontecer uma espécie de reserva de mercado para o grupo, que passa a se reproduzir, não por suas condições estruturalmente desiguais, mas pelo próprio espaço conquistado.

Young discute extensivamente esse tipo de argumento no capítulo intitulado "Social difference as political resource". Enfatiza, em primeiro lugar, que em sociedades com alto grau de desigualdade, a não diferenciação tem como conseqüência o fato de que o interesse dos mais poderosos e ricos tornar-se-ão os interesses comuns (2000, p. 109). A autora pensa em um público democrático que deve ser "plenamente inclusivo de todos os grupos sociais porque a pluralidade de perspecti- 
va que eles oferecem para o público ajuda a desvendar a realidade e a objetividade do mundo no qual dão conta juntos" (Idem, p. 112). Todavia, uma questão permanece em aberto: os grupos que conseguem espaço em algum tipo de inclusão são capazes de se organizar como diferenças, mas em sociedades que apresentam grandes desigualdades sociais, há um significativo contingente da população que é incapaz de se constituir como diferença na esfera pública, devido a condições de pobreza extrema, isolamento social e falta de recursos providos pela educação formal.

A questão fundamental, então, reside na dicotomia democracia e inclusão. O que pode parecer à primeira vista uma afirmação que beira o lugar comum, revela uma problemática das mais centrais para a teoria democrática. Uma vez que a inclusão não ocorre por meio do apagamento daquilo que condiciona a exclusão, mas, justamente, pela reafirmação desse condicionante, o processo de inclusão provoca mudanças radicais que rearranjam a posição relativa dos sujeitos que já estavam plenamente inseridos na sociedade. Tomando o poder como uma equação de soma zero, ver-se-á que para cada sujeito-grupo incluído corresponde alguma perda de poder para um grupo anteriormente incluído. Isso explica em muitas medidas as dificuldades das experiências participativas.

É verdade, como afirma Young, que a inclusão alarga o espaço democrático e, ainda, a possibilidade de justiça, já que a presença do outro leva a "um entendimento mais compreensivo que toma em consideração o interesse do outro". Trata-se, seguindo a raciocínio da autora, do público democrático, idéia que não comportaria uma noção de generalidade, mas o que chama de interação social ou princípio de justiça. Entretanto, os avanços rumo à formação desse tipo de público têm sido, nas experiências concretas, lentos e complexos, exatamente porque envolvem perda de poder por parte dos que já se encontram incluídos. Nos casos discutidos na primeira parte deste artigo, essa situação pode ser verificada tanto no exemplo da África do Sul, como nas bem-sucedidas experiências de Porto Alegre e Kerala.

A crise na experiência de participação na África do Sul é especialmente ilustrativa, pois o movimento participativo ocorreu em uma situação de total exclusão, não havendo qualquer possibilidade de formação de um público democrático. Foi o total fechamento provocado pelo apartheid que possibilitou um espaço alternativo. ${ }^{4}$ Com o fim do regime e a instauração de um Estado democrático de direito, não ocorreu, como esperado, a inclusão dos grupos outsiders como grupos diferenciados, mas sua incorporação dentro de uma perspectiva de cidadania liberal (universal). Não haveria razão (salvo de ordem puramente ética) para a inserção de grupos que haviam se organizado em virtude de uma exclusão que não mais existia. O reconhecimento de um novo acordo circunscrito na idéia de um público democrático certamente fragilizaria o próprio pacto, pois exporia diferenças e lutas de poder. Essa discussão não pretende ser uma teoria justificatória da impossibilidade dos processos participativos, mas indica as dificuldades de consolidação desses processos, sobretudo em circunstâncias de mudança radical, onde ao menos em tese seriam mais necessários.

Nos casos de Porto Alegre e Kerala há claramente uma redistribuição de poder a partir da existência de uma autoridade interessada em um novo arranjo do poder municipal, no primeiro caso, e estadual, no segundo. A questão que permanece aqui é até que ponto essas experiências podem se tornar redes de transmissão de poder de uma elite política para outra, no caso de uma elite que domina o legislativo para outra que domina o executivo. Se isso pode ocorrer de maneira conjuntural, não é, contudo, suficiente para anular os efeitos de inclusão, que parecem inegáveis.

As preocupações de Young com processos que envolvem a inclusão não se limitam a experiências participativas, pois para ela é fundamental a discussão em torno noção de representação nas democracias modernas: "Em uma sociedade de massa, para que a política seja realmente democrática, a representação e a participação exigem uma reciprocidade permanente" (Young, 2000, p. 124). No capítulo intitulado "Representation and social perspective", Young analisa a questão da representação tomando quatro temas principais: o próprio conceito de representação, a accountability, os modos de representação e a representação 
de grupos excluídos. Afirma que se a representação for entendida como um processo que envolve identidade, isto é, o representante age como substituto do representado - no lugar de - reproduzindo cada um e todos os interesses, então a representação, embora seja necessária, torna-se uma impossibilidade. Daí, argumentar que a noção de representação deve ser entendida, não como identidade, mas como diferença, se valendo, para isso, do conceito de diferença de Jaques Derrida:

Conceitualizar a representação em termos da difference significa reconhecer e afirmar que existe a diferença e a separação entre os representantes e os eleitores. Evidentemente, nenhuma pessoa pode pretender ser ou falar como uma pluralidade de outras pessoas. A função do representante de falar por não deveria ser confundida com o requisito de identificação que o representante fala como os representados falariam, tratando de ser presente por eles em suas ausências (Young, 2000, p. 127).

A idéia de separação entre representantes e representados é fundamental para que se possa, inclusive, delimitar o espaço da política; sem ela esse espaço simplesmente não existiria. O apagamento dessa separação seria, em última instância, a utopia do fim do político como um espaço distinto da sociedade. Ora, tal distância também deve ser compreendida como a distância entre interesses individuais (privados) e interesses coletivos (públicos). Dito de outra forma, o problema existe quando não está presente a representação dos interesses coletivo, ou quando o conteúdo do interesse coletivo passa a não abranger parte significativa dos interesses em disputa. A questão, portanto, apresenta-se de forma diversa, ou seja, não se localiza na distância entre representantes e representados, mas na relação estabelecida entre eles, onde deve estar presente conteúdos tanto de autorização, como de accountability. A autorização é necessária pela própria condição de espaço público de discussão e deliberação em que se constituem os parlamentos. Os representantes têm determinações partidárias estratégicas a seguir, assim como sua própria tomada de decisão, a qual não pode ser antecipada ao representado. Entretanto, para que essa relação não perca o sentido, é fundamental, segundo Young, a presença de accountabiliy:

Uma democracia fortemente comunicativa, entretanto, também requer alguns processos e procedimentos em que os representados chamam os representantes para prestar conta e, sobretudo, para reautorizá-los. Tal como com a autorização, $a c$ countability deve ocorrer tanto por meio das instituições oficiais, como, na vida pública, de associações cívicas independentes (Young, 2000, p. 132).

A relação entre a sociedade civil organizada e a representação é especialmente importante quando se está focando questões relacionadas à deliberação e a processos de inclusão, pois, ou estes últimos não consideram a possibilidade da representação, ou os modelos deliberativos devem enfrentar as questões da relação entre participação deliberativa e representação. Uma vez que a representação não pode ser reduzida a uma simples delegação, como muito bem enfatiza Young, essa relação se torna ainda mais complexa. As esferas deliberativas podem, em alguns casos, competir com a esfera representativa no estreito limite do espaço político institucional, levando o instituto da representação a uma posição muito próxima de uma simples delegação. Em outras situações, pode-se encontrar uma espécie de divisão de trabalho, em que a sociedade civil organizada ficaria "fora" do campo político, como uma espécie de reserva virtuosa capaz de provocar a accountability. Não se trata aqui de considerar a sociedade civil o monopólio da virtude, mas é razoável afirmar que a sociedade como tal possui um grande potencial para exercer com êxito esse papel. Há exemplos interessantes disso, mesmo em sociedades caracterizadas pela desigualdade e pela exclusão, como a brasileira. Nos últimos anos, tem-se observado resultados positivos de reversão a partir de movimentos recorrentes em cidades pequenas no Brasil contra, por exemplo, a corrupção do poder público ou os aumentos abusivos dos salários de vereadores.

Mesmo considerando as formas de relacionamento de representantes e representados em todas as dimensões, até que ponto os instrumentos de accountability e a própria deliberação têm con- 
dições de modificar a composição do corpo de representantes? Em princípio, parece que essas relações podem enfraquecer ou mesmo isolar as instituições representativas, mas per se não têm instrumentos de intervenção capazes de modificar sua composição. Daí se poder pensar em duas possibilidades perversas: o enfraquecimento da representação pelo desinteresse da sociedade civil organizada em tomar parte dela ou a manutenção dos órgãos representativos como "reserva de mercado" das elites político-partidárias. As soluções apresentadas a esses dilemas geralmente apontam para a representação baseada em políticas do tipo "cotas", que seria uma forma de romper tanto com o isolamento, como com o elitismo. Entretanto, essas políticas têm sido foco de uma constante controvérsia, que gira em torno de três pontos principais: ruptura da universalidade da representação; privilegiar um grupo em relação a outros; naturalização de identidades e/ou posições de grupos na estrutura social.

Iris Young faz uma instigante discussão a respeito dessa questão, identificando três formas de representação: de interesses, de princípios e de perspectivas sociais. Interesse é o mais simples e imediato modo de representação e diz respeito a demandas de indivíduos ou grupos para atingir objetivos específicos. Representação de opinião abrange um espectro que vai de questões relativas a valores éticos e morais até ideologias, que poderiam ser chamadas de opiniões propriamente políticas. A autora identifica os partidos políticos como um veículo de expressão de opiniões, ou seja, como um dos partícipes no mosaico que forma as questões de participação e representação, concepção quase nunca presente em discussões teóricas dessa ordem. Os partidos e a própria idéia de representação nas teorias de democracia deliberativa, participativa e associativa ocupam uma posição muito ambígua: se nenhuma delas, explicitamente, abre mão da existência dos partidos, dificilmente os articulam em suas propostas de discussão teórica. Mesmo Young, considerando-os um espaço de representação de opiniões, o que sugeriria um outro encaminhamento de sua argumentação, rapidamente, traz os partidos para um plano secundário. "Associações mais especializadas e menores po- dem e com freqüência são criadas para representar opiniões na vida pública e influenciar políticas públicas" (Young, 2000, p. 135).

A terceira forma é a mais complexa e referese à questão da representação de grupos. Young parte da idéia de que a representação de grupo não cria "divisão e conflito", mas, ao contrário, é essencial para que haja justiça no interior da democracia, pois os problemas e as soluções encontradas passam a ser discutidos em diferentes perspectivas. Perspectiva social, para autora, consiste em "um conjunto de questões, tipos de experiências e presunção com os quais o raciocínio começa, em vez de direcionar a conclusão " (Idem, p. 137). A perspectiva social não tem conteúdos específicos e exatamente por isso é o ponto de vista a partir do qual os grupos podem se posicionar. Young exemplifica essa idéia ao descrever um jornal publicado pela comunidade negra de Pittsburg nos Estados Unidos. Segundo a autora, esse jornal reúne um conjunto de interesses e opiniões diferenciadas, mesmo partindo da perspectiva da comunidade negra, ou tratando de temas que interessam especificamente a essa comunidade, ou, ainda, dando notícias sobre os eventos, mesmo quando trata de questões locais e nacionais não diretamente ligadas aos negros (Young, 2000, p. 138).

A autora defende, ainda, que a noção de perspectiva seria a forma mais apropriada de representação, pois evitaria a formação de grupos atraídos pela representação de interesses ou de opiniões. Deriva-se dessa posição uma série de questões, algumas resolvidas no texto pela autora, outras não. A primeira diz respeito às formas pelas quais os indivíduos vivem essas perspectivas. Em uma sociedade complexa o indivíduo vai se identificar com uma ou outra perspectiva de acordo com as formas de sua interação social. Mas isso, no entanto, não parece ser tão simples: certamente a perspectiva, como bem aponta a autora, tem raízes históricas e estruturais, mas parece difícil pensar que possa se constituir publicamente, a não ser a partir de um núcleo que "a constrói" como significativa. Uma pessoa negra, mulher ou jovem pode agir "naturalmente" a partir da perspectiva de ser negro, mulher ou jovem. Outra coi- 
sa é viver publicamente - conscientemente - a partir dessa perspectiva: é nesse segundo cenário que se pode pensar uma representação de perspectivas. Não há, nesse sentido, uma perspectiva do ponto de vista da mulher antes do movimento feminista, ou do negro antes do movimento negro; em outras palavras, poderia haver perspectivas vividas individualmente, as quais, inclusive, lhes excluía da participação.

A segunda questão diz respeito à diferença entre a noção de perspectiva e a de interesses e opiniões. Parece ser bastante correto o argumento de Young de que a primeira oferece muito mais abertura do que a formação de grupos de interesses ou grupos ideológicos. O que me interessa, aqui, no entanto, é chamar atenção para o fato de que não se pode descartar facilmente a possibilidade de que grupos calcados em perspectivas não possam ser também grupos de interesse e até de opinião. Isso contraria a idéia de que não há possibilidade de ilegitimidade em perspectivas. Se for tomado como exemplo uma população branca economicamente dominante, que vive entre uma maioria negra, facilmente a perspectiva desta população branca poderia se confundir com uma ideologia racista e com interesses excludentes.

A solução de Young aponta para cenários muito promissores em relação às formas de representação de grupos sociais excluídos: no caso de mulheres e negros, a noção de perspectiva parece bastante adequada, justamente por causa da dispersão desses atores em termos de classe social, cultura, níveis educacionais e religião. Mesmo a construção da perspectiva por um núcleo não ameaça a existência da diversidade. Entretanto, no caso de grupos menos dispersos, que por sua própria história de exclusão foram forçados a se segregar, como etnias ou culturas perseguidas ou muito desvalorizadas em um dado contexto, sua possibilidade de representação por meio da idéia de perspectiva parece mais difícil de se concretizar, uma vez que essa noção pode se confundir com opinião ou o simples interesse.

Partindo da premissa de que é desejável que as perspectivas de grupos sociais até então excluídos sejam representadas, Young avança na discussão no sentido de mostrar como a representa- ção deve ocorrer. Seriam as cotas um bom sistema para resolver o problema da exclusão? A autora é bastante enfática em defender a necessidade de ações positivas que abram espaço para que realmente os grupos sociais excluídos encontrem uma possibilidade de participação política. Entretanto, ela não ignora os problemas decorrentes de políticas protetoras do tipo "cotas", tais como posturas corporativas e congelamento de identidades. Young claramente defende uma política de presença dos grupos excluídos, afirmando que é bastante difícil pensar que alguém de fora de um grupo possa realmente representar a perspectiva deste. Também defende que a perspectiva de um grupo será melhor representada à medida que houver uma maior número de representantes. A solução que apresenta para organizar esse tipo de representação é recorrente na literatura:

[...] cotas para mulheres nas listas partidárias, ou regras sobre certa proporção de membros de grupos minoritários raciais ou étnicos em convenção partidária são freqüentemente formas aceitáveis e desejáveis de promover a inclusão de interesses e perspectivas diversas. Esse método não torna o grupo um gueto, mas inclui seus membros em deliberações partidárias mais amplas. Dependendo do número de partidos e dos procedimentos de votação, os grupos continuam tendo variadas opções de candidatos (Young, 2000, p. 150).

Assim como Young, parece-me que a política das cotas é uma solução bastante eficiente como estratégia de inclusão. Gostaria, entretanto, de fazer algumas considerações a respeito. Quanto à justiça da representação, questiono se está-se considerando justo a representação de um segmento social excluído ou de um grupo social com uma perspectiva particular? Como já foi observado anteriormente, um indivíduo tem uma gama de perspectivas à sua disposição e não há nada, a priori, que defina com qual ele se identificará. Uma mulher ou um negro, por exemplo, podem ser representantes de seus grupos e, no entanto, sua ação pode não corresponder a uma perspectiva esperada. Os defensores das cotas ou de outro tipo de ação positiva parecem sempre estar pensando em uma representação qualificada, diferente da exigi- 
da para os já "normalmente" incluídos. Longe de se defender aqui uma representação de tipo "espelho", pode-se, todavia, argumentar de que é injusto o fato de no Congresso Nacional Brasileiro existir menos de 10\% de congressistas mulheres, e menos ainda de negros. Seria igualmente correto inferir desses dados que, se os percentuais fossem duas ou três vezes maiores, haveria mais justiça. Em princípio, isso também não garantiria a presença da representação de uma determinada perspectiva, pois a identificação com tal ou qual perspectiva é um processo que pode ou não ocorrer. Quando se trata de grupos sociais, é necessário supor um processo de inclusão, mesmo que informal, com uma certa organicidade dada pela perspectiva de cada grupo; quando pensamos em segmentos sociais, o processo envolve apenas a identificação de sua existência na estrutura social, embora essa presença seja fundamental tanto em relação ao princípio de justiça, como pela potencialidade que tais segmentos têm de incorporar uma perspectiva a partir da interação com grupos da sociedade civil. Isso depende, contudo, da capacidade organizativa da sociedade civil e de seu poder de pressão e intervenção no campo político.

O último capítulo do livro de Iris Young, intitulado "Civil society and its limits" é fundamental para a análise que estou aqui empreendendo, pois traz para o centro da discussão o papel da sociedade civil. A autora analisa "a função e os limites da associação cívica no contexto de sociedades guiadas por leis, as quais reconhecem liberdades básicas, têm práticas políticas democráticas, mas mantêm um quadro de injustiça estrutural" (Young, 2000, p. 155).

Young define sociedade civil como um espaço amplo de auto-organização de grupos que não se expressam por meio de discursos políticos e onde há um grande potencial para a inovação social e a criação de serviços que não visem ao lucro. Posicionando-se contra aqueles que consideram a sociedade civil o sucedâneo do Estado, a autora é enfática em afirmar que, para uma democracia, o Estado tem funções a exercer que são insubstituíveis. Para demarcar a distinção entre os espaços da sociedade civil e do Estado e os potenciais de ação de cada um, Young introduz duas noções importantes, a saber, dominação e opressão. Dominação é definida como "condições institucionais que inibem ou impedem pessoas de participar na decisão e no processo que determina suas ações e as condições de suas ações" (Idem, p. 156). Opressão

[...] consiste em processos institucionais sistemáticos que previnem as pessoas de aprenderem e usarem habilidades satisfatórias ou expansivas em cenários socialmente reconhecidos; ou que inibe suas habilidades de interação e de comunicação ou, ainda, de expressão de sentimentos e perspectivas sobre a vida social em contextos onde os outros possam lhes ouvir (Idem, p. 156).

É, portanto, no espaço da sociedade civil que a autora identifica a possibilidade do surgimento da esfera pública, local de formação de opinião política e de exercício de accountability. O que é interessante e bastante original no pensamento de Young é a identificação que faz das possibilidades de superação dessas duas condições: a autodeterminação pode ser promovida pela sociedade civil organizada; já o autodesenvolvimento, por ser conseqüência de injustiças estruturais, depende de políticas estatais.

Young analisa a sociedade civil a partir da identificação de três níveis de vida associativa: privado, cívico e político. As associações privadas são formadas por membros com afinidades e identidades específicas - família, clubes sociais, festas privadas, organizações religiosas, entre outros. As cívicas, em princípio, estão abertas a qualquer um e têm na maioria das vezes o propósito específico de servir uma causa - por exemplo, o trabalho voluntário. Finalmente, as associações políticas são aquelas que pretendem influenciar o Estado, tratam-se de lobbies e organizações que defendem interesses especiais, cuja função é politizar a vida social e econômica. Young contrapõe sua classificação à realizada por Arato e Cohen (1999), os quais dividem as organizações da sociedade civil em duas esferas: defensivas, que correspondem ao que Young chama de privadas e algumas cívicas; e ofensivas, que abrangem algumas atividades das associações cívicas somadas às políticas. O primeiro grupo re- 
fere-se à auto-organização da sociedade; o segundo, às atividades da esfera pública. A autora destaca a possibilidade que essas atividades têm de dar voz aos excluídos em um espaço livre de coerção institucional e da luta política, assim como de gerar serviços que estão fora da alçada do Estado ou do interesse da economia de mercado. Mas é com as atividades da esfera pública que Young está particularmente preocupada, pois se trata de um espaço de encontro entre os políticos e a sociedade e, portanto, propício para experiências de democracia deliberativa.

O primeiro aspecto importante que Young chama a atenção é o fato de que em sociedades complexas a esfera pública não pode ser pensada como um local, mas como um conjunto de ações dispersas no tempo e no espaço, cujas principais características são a abertura para todos que desejarem fazer parte, referir-se à relação entre cidadãos e ter uma forma específica de trazer os temas a público. Para a autora, sua atribuição fundamental é a de estabelecer relação entre as pessoas e o poder. E isso ocorre a partir de três funções: oposição e accontability; influência sobre as políticas; transformação da sociedade por meio da própria sociedade. As duas primeiras funções indicam tanto o papel de árbitro da sociedade no controle das políticas públicas, como de força auxiliar do mundo propriamente político. Tais funções são tão importantes quanto limitadas, e, possivelmente, é nesse limite que habita as virtudes da sociedade civil. Em contrapartida, essas limitações podem estar apontando para as próprias limitações da deliberação e da participação.

No que pese a centralidade das duas primeiras funções, é a terceira que permite ver a esfera pública como construtora de comportamentos, princípios e valores. Young apresenta como exemplo os movimentos feminista e ambientalista, os quais além de atuarem fazendo oposição, buscando accountbility e influenciando políticas, foram responsáveis pela mudança de mentalidade das populações ocidentais sobre os direitos das mulheres e sobre a responsabilidade de cada um pelo equilíbrio ecológico do planeta. Se isso é fundamental quando se pensa em uma democracia mais justa, não seria de menor grau a "construção" de uma perspectiva social. Anteriormente, chamei a atenção para o fato de que os indivíduos não aderem naturalmente às suas perspectivas sociais. Como bem apontou Young, o sujeito está circunscrito num meio que apresenta diversas perspectivas, com as quais poderá se identificar; isso, no entanto, não depende somente de uma decisão pessoal, mas das maneiras que essas perspectivas estão sendo trabalhadas na esfera pública. Daí que qualquer forma de representação de perspectivas sociais depende em grande medida das possibilidades geradas na esfera pública.

Para Young a sociedade civil tem grande potencial para promover a autodeterminação, que se contrapõe à opressão, o que não ocorre com a mesma envergadura em relação ao autodesenvolvimento, que se contrapõe à dominação. Fazendo uma crítica arguta aos argumentos libertários, comunitaristas e pós-marxistas contra o Estado, a autora apresenta este como central na promoção do autodesenvolvimento, uma vez que ele pode garantir necessidades básicas, tais como alimentação, saúde, educação, treinamento, infra-estrutura urbana, laser etc.

As associações da sociedade civil certamente po-
dem dar conta das falhas de firmas e mercados
para possibilitar o exercício de capacidades. En-
tretanto, a sociedade civil por si só não pode fa-
zer a trabalho maior de dirigir os investimentos
no sentido de suprir necessidades e desenvolver
habilidades, empregando de maneira útil seus
membros (Young, 2000, p. 186).

Young conclui o capítulo apontando para um impasse: uma democracia robusta necessita tanto da presença do Estado como de uma sociedade civil forte, entretanto as atividades de um podem, muitas vezes, minar as do outro. Enquanto o Estado tende a tornar o cidadão passivo, a sociedade civil é o espaço fecundo para a competição direta de uma multiplicidade de organizações. Como solução, Young examina duas propostas de democracia associativa, a de Hirst (1999) e a de Cohen e Rogers. Hirst propõe uma nova forma de democracia, em que as associações voluntárias autogeridas democraticamente seriam centrais na formação social, e ao Estado caberia arrecadar impostos 
para manter as associações e criar regras de funcionamento e padrões de serviço. Cohen e Roger enfatizam a necessidade de compensar as desigualdades por meio de uma representação promovida por associações da sociedade civil, as quais trabalhariam bastante ligadas ao Estado.

Young acredita que a noção de democracia associativa abre uma nova perspectiva no debate sobre os problemas da sociedade contemporânea, pois nesse modelo as associações civis e o Estado funcionam como uma espécie de contrapeso. Para finalizar, a autora propõe uma série de questões em torno dessa idéia, as quais certamente ampliam o espaço de discussão:

Devemos pensar a democracia associativa como a forma de organização de toda a sociedade ou como um entre muitos outros instrumentos? Se os Estados decidem organizar e subsidiar as associações, por quais processo e critério isso deve ser feito? Como a democracia associativa enfrentaria os conflitos e desacordos que certamente apareceriam em cada uma dessas questões (Young, 2000, p. 193).

\section{À guisa de conclusão}

Para finalizar este texto gostaria de retomar algumas questões levantadas na primeira parte à luz das idéias de Young e concluir discutindo a seguinte questão: Os estudiosos de casos de experiências de democracia participativa, assim como as análises teóricas, como a de Iris Young, defendem a importância e revelam as virtudes da organização da sociedade civil, mas não conseguem visualizar com clareza o estabelecimento do encontro entre essa sociedade e a política institucional. Os estudos de caso mostram que a sociedade civil tem êxito em se organizar quando há uma ausência quase total do Estado, ou, ao contrário, quando o Estado assume grande parcela de responsabilidade nessa organização. No estudo de Young pode-se vislumbrar uma ponte possível entre a sociedade civil e o Estado, mas ao discutir a representação dos indivíduos ou de grupos a autora tem dificuldade em apresentar suas formas de ocorrência. Há um grande ausente em todas essas discussões: os partidos políticos, esferas propriamente políticas de manifestação de vontades, interesses e perspectivas, são renegados a um segundo plano: nos estudos de caso aparecem ou como estorvo, ou como local de corrupção e privilégio; nos estudos teóricos, estão praticamente ausentes.

Não pretendo responder às três questões finais que Young propõe, mas trazer subsídios para a discussão em pauta. Sobre o alcance da democracia associativa, parece mais razoável pensar que a resposta não se encontra na restrição das possibilidades, mas na capacidade de desenvolver instrumentos de interação entre a sociedade civil e a política institucional. A teoria normativa da democracia associativa (como de resto outras formas de democracia participativa) não parece ter desenvolvido um arcabouço institucional capaz de assegurar realmente o processo democrático, isto é, não criou pesos e contrapesos capazes de evitar as distorções no processo participativo, como, por exemplo, a superparticipação de um grupo ou uma hipertrofiada presença do Estado na organização da participação. Em contrapartida, a solução que considera a utilidade da democracia de tipo participativa somente para determinados espaços pode facilmente levar a uma espécie de divisão de trabalho, que manteria intocadas as esferas de poder das instituições geridas pela representação.

Se partirmos do fato de que o Estado de que se está falando seja um Estado democrático, há sempre um certo nível de representação no poder legislativo, daí que a democracia não pode abrir mão da representação partidária, o único canal pelo qual as políticas públicas, no sentido de subsidiar as organizações civis, devem ser pleiteadas. A decisão do Estado não deve ser burocrática, mas uma decisão sempre política. O que parece ficar sem guarida são justamente aqueles contingentes mais desprovidos de condições econômicas, sociais e educacionais, os quais sempre dependerão da voz e da solidariedade de outros segmentos. Ou seja, quem não tiver nenhum espaço de representação tenderá a reproduzir sua exclusão, mesmo em espaços participativos. A última questão de Young só se constitui em um problema se estiver implícito um ideal de sociedade harmônica, livre das rela- 
ções de poder. Se este não for o caso, deve-se ter em mente que qualquer processo democrático para ser bem-sucedido necessita ter capacidade de gerir conflitos e, quanto mais houver processos de inclusão das diferenças, mais haverá a possibilidade de desacordo, conflito e discussão.

\section{Notas}

1 Os resultados do projeto foram publicados em Santos (2002)

2 Todas as citações de Young (2000) são de minha tradução.

3 A noção de política de presença está sendo utilizada aqui em contraposição à política de idéias, conceitos esses desenvolvidos por Anne Phillip ao longo de sua obra, mas sobretudo em seu livro Democracy and difference e no capítulo "Dealing with difference: a politics of idea or a politics of presence?" (ver Phillip, 1996).

4 A ausência de fato do Estado em algumas regiões da Colômbia parece provocar fenômeno semelhante. Faz parte dos estudos de caso do projeto de pesquisa dirigido por Souza Santos (2000) dois capítulos que tratam da experiência colombiana, ver Ramirez (2000) e Uribe (2000).

\section{BIBLIOGRAFIA}

ARATO, L. \& COHEN, J. (1999), Civil society and political theory. Cambridge, MIT Press.

AVRITZER, Leonardo. (2002), "Modelos de deliberação democrática: uma análise dos orçamentos participativos no Brasil", in Boaventura de Souza Santos (org.), Democratizar a democracia: os caminhos da democracia participativa, Rio de Janeiro, Civilização Brasileira.

BUHLUNGU, Sakheda. "O reinventar da democracia participativa na África do Sul”, in Boaventura de Souza Santos (org.), Democratizar a democracia: os caminhos da democracia participativa, Rio de Janeiro, Civilização Brasileira.
COHEN, Joshua. (1986), "An epistemic conception of democracy". Ethics, 97, out.

COHEN, Joshua \& ROGERS, Joel. (1996), "Secondary associations and democratic governance", in Eric Wright, Eric. (eds.). (1996), Associations and democracy, Londres, Verso.

DAVID, Lawrence. (2002), "Os movimentos sociais em Porto Alegre" (mimeo.).

HELLER, Partrik \& ISAAC, T. M. Thomas. (2002), "O perfil político e institucional da democracia participativa: lições de Kerala, Índia", in Boaventura de Souza Santos (org.), Democratizar a democracia: os caminhos da democracia participativa, Rio de Janeiro, Civilização Brasileira.

HIRST, Paul. (1990), Representative democracy and its limits. Oxford, Polity Press.

PHILLIP, Anne. (1993), Democracy and difference. Cambridge, Polity Press.

. (1996), "Dealing with difference: a politics of idea or a politics of presence?", in S. Benhabib (ed.), Democracy and difference, New Jersey, Princeton University Press.

RAMIREZ, Maria Clemência. (2002), "A política do reconhecimento e da cidadania no $\mathrm{Pu}-$ tumayo e na Baixa Bota Caucana: o caso do movimento cocalero de 1996", in Boaventura de Souza Santos (org.), Democratizar a democracia: os caminhos da democracia participativa, Rio de Janeiro, Civilização Brasileira.

ROGERS, John. (1985), "On the degeneration of the public sphere". Political Studies, 32.

SANTOS, Boaventura de Souza (org.). (2002), Democratizar a democracia: os caminhos da democracia participativa. Rio de Janeiro, Civilização Brasileira.

(2002a), "Orçamento participativo em Porto Alegre: para uma democracia redistributiva", in Boaventura de Souza 
Santos (org.), Democratizar a democracia: os caminhos da democracia participativa, Rio de Janeiro, Civilização Brasileira.

SHEITH, D. L. (2002), "Micromovimentos na Índia: para uma nova política participativa", in Boaventura de Souza Santos (org.), Democratizar a democracia: os caminhos da democracia participativa, Rio de Janeiro, Civilização Brasileira.

URIBE, Maria Tereza de H. (2002), "Emancipação social em um contexto de guerra prolongada: o caso da Comunidade de Paz de San José de Apartadó, Colômbia”, in Boaventura de Souza Santos (org.), Democratizar a democracia: os caminhos da democracia participativa, Rio de Janeiro, Civilização Brasileira.

YOUNG, Iris. (2000), Inclusion and democracy. Oxford, Oxford University Press. 


\section{ESPAÇOS DELIBERATIVOS E A QUESTÃO DA REPRESEN- TAÇÃO}

Céli Regina Jardim Pinto

\section{Palavras-chave}

Representação; Sociedade civil; Participação; Movimento social

Este artigo parte do pressuposto de que a dificuldade de se enfrentar a relação entre questões de deliberação e questões de representatividade constitui um sério estrangulamento tanto no âmbito teórico como na esfera das experiências concretas. Na primeira parte, examina-se um conjunto de experiências participativas estudadas em diversas regiões em uma pesquisa coordenada por Boaventura de Souza Santos. $\mathrm{Na}$ segunda, discute-se essas experiências à luz das propostas de Iris Young, em Inclusion and democra$c y$, sobre participação e representação.

\section{DELIBERATIVE SPACE AND THE PROBLEM OF REPRE- SENTATION}

Céli Regina Jardim Pinto

\section{Keywords}

Representation; Civil society; Participation; Social movement.

The article presupposes that the difficulty of dealing with the relationship between deliberation and representation problems represents a serious drawback in both the theoretical and concrete experiences ambits. Firstly it analyses a research coordinated by Boaventura de Souza Santos about participative experiences in several regions. It then discusses those experiences in light of the propositions of Irys Young in her last book, Inclusion and Democracy, in which participation and representation are analyzed.

\section{EPACES DÉLIBÉRATIFS ET LA QUESTION DE LA REPRÉSEN- TATION}

Céli Regina Jardim Pinto

\section{Mots-clés}

Représentation; Société civile; Participation; Mouvement social.

Cet article part de l'hypothèse que la difficulté d'affronter le rapport entre des questions de délibération et des questions de représentation constitue un grave étranglement aussi bien du point de vue théorique que dans la sphère des expériences concrètes. Dans une première partie, l'auteur examine un ensemble d'expériences participatives étudiées dans plusieurs régions d'après une recherche coordonnée par Boaventura de Souza Santos. Dans la seconde, ces expériences sont discutées à la lumière des propositions de Iris Young, dans Inclusion and democracy, à propos de la participation et de la représentation. 